\title{
ESTUDO DE UM CASO DE FRENTE FRIA SECUNDÁRIA SOBRE O SUL DO BRASIL
}

\author{
CLAUDINÉIA BRAZIL SALDANHA ${ }^{1}$, NATALIA FEDOROVA², MARIA HELENA DE CARVALHO ${ }^{3}$ \\ ${ }^{1}$ Centro Estadual de Sensoriamento Remoto e Meteorologia, Universidade Federal do Rio Grande do Sul, \\ Porto Alegre, RS, Brasil \\ ${ }^{2}$ Departamento de Meteorologia, Centro de Ciências Exatas e Naturais, Universidade Federal de Alagoas \\ (UFAL), Maceió, Alagoas, Brasil \\ ${ }^{3}$ Departamento de Meteorologia, Faculdade de Meteorologia, Universidade Federal de Pelotas, Pelotas, RS
}

neiabrazil@yahoo.com.br, natalia@ccen.ufal.br, mhelena@ufpel.edu.br

Recebido Dezembro 2001 - Aceito Novembro 2009

\begin{abstract}
RESUMO
Neste trabalho foi feita uma análise da situação sinótica e dos parâmetros meteorológicos associados a uma frente fria secundária que se formou no ar frio, na retaguarda da frente fria. Esta frente esteve associada a neve, a precipitações intensas espalhadas e a baixa visibilidade no estado do Rio Grande do Sul. Foram utilizados dados fornecidos pelo NCEP, imagens do satélite GOES no canal infravermelho, dados de estações meteorológicas do Rio Grande do Sul, cedidos pelo Oitavo Distrito de Meteorologia e dados de radiossondagem do aeroporto Salgado Filho. Estudaram-se as distribuições horizontal e vertical (pelos campos, perfis verticais e seções verticais perpendiculares à frente e ao longo da mesma) dos vários parâmetros meteorológicos, tais como, temperatura, pressão, umidade, vorticidade relativa e outros, do modelo do NCEP, para a identificação da posição e da estrutura espacial da frente secundária. Calcularam-se índices de instabilidade (K, Showalter, Totals, Sweat e índice de levantamento) e energia para verificar o comportamento e a instabilidade da atmosfera na região da frente fria secundária. A frente secundária foi observada claramente na imagem de satélite e nos campos de temperatura, umidade, divergência de umidade, em baixos níveis, e de advecção de vorticidade no nível de $500 \mathrm{hPa}$.

Palavras-chave: frente fria secundária, previsão do tempo, meteorologia sinótica
\end{abstract}

\begin{abstract}
CASE STUDY OF A SECONDARY COLD FRONT OVER SOUTHERN BRAZIL

In this work an analysis of the synoptic situation and of the meteorological parameters associated to a secondary cold front formed in the rear of a cold front was performed. That front was associated with snow, scattered intense precipitations and low visibility in the Rio Grande do Sul State. Data from NCEP, GOES satellite infrared image, "Oitavo Distrito de Meteorologia" meteorological stations and upper air data from Salgado Filho airport were used. The horizontal and vertical distributions (using the fields, vertical profiles and cross sections perpendicular to the front and along it) of several meteorological parameters, such as, temperature, pressure, humidity, relative vorticity and others, from the NCEP model, were analyzed in order to identify the position and spatial structure of the secondary front. Instability indices (K, Showalter, Totals, Sweat and Lifted Index) and the convective available potential energy were calculated for the region of the secondary cold front. This front was clearly observed in the satellite images and in the temperature, humidity and humidity divergence fields at low levels and in the vorticity advection field at $500 \mathrm{hPa}$ level.
\end{abstract}

Keywords: secondary cold front; weather forecasting; synoptic meteorology 


\section{INTRODUÇÃO}

Os sistemas sinóticos na escala intermediária têm dimensões horizontais da ordem de 1000 a $2000 \mathrm{~km} \mathrm{e}$ duração de 0,5 até 2 dias. (Bonatti, 1988). Três tipos dos processos de ciclogênese nesta escala foram descritos pela primeira vez por Zillman e Price (1972). Estes três processos são: 1) desenvolvimento de nuvens vírgula dentro do ar frio, 2) desenvolvimento de uma oclusão instantânea e 3) desenvolvimento de uma onda frontal. Esta classificação foi feita de acordo com a distância entre as nuvens convectivas em forma vírgula e a banda de nebulosidade da frente polar. As nuvens convectivas em forma vírgula são associadas com um cavado dos altos níveis, ou com a anomalia da vorticidade potencial; todavia, a frente polar está associada com uma zona de baroclinia. A formação dos tipos um e dois está ligada com a formação do cavado de onda curta. Esta classificação é importante até agora e foi citada em muitos trabalhos; por exemplo, em Bonatti (1988), Reeder e Smith (1998) e Browning (1999).

Reed (1979) estudou dois casos de ciclogênese, que ocorreram no lado polar da corrente de jato nos níveis médios e altos na região, com forte cisalhamento ciclônico horizontal. Baseados em resultados dos estudos e em outras evidências, são descritas características destes tipos de distúrbios. Os ciclones são geralmente de pequena dimensão, no intervalo de $1000-1500 \mathrm{~km}$. O aquecimento nos baixos níveis é uma das condições necessárias para o desenvolvimento destes sistemas. Os pequenos ciclones se formam freqüentemente no inverno sobre os oceanos, originando aquecimento em regiões de baixos níveis e aumentando a convecção, formando nuvens em forma de vírgula. As camadas condicionalmente instáveis atingem a altura de $500 \mathrm{hPa}$. Tanto a instabilidade baroclínica, quanto a barotrópica são importantes para formação destes sistemas.

Uma análise do desenvolvimento de uma nuvem vírgula inteiramente dentro do ar frio sobre o Paraguai, norte da Argentina e sul do Brasil foi feita por Bonatti (1988). Este sistema sinótico foi formado sobre uma baixa relativamente quente, observada na carta de pressão à superfície, com ligeira preferência para as estações de transição. Foi notado um duplo máximo no vento na direção vertical (700 e $200 \mathrm{hPa}$ ). Esse duplo máximo sugere que a liberação de calor latente é importante para o desenvolvimento da perturbação. Uma onda curta no campo de temperatura apresentou concentração de isotermas com orientação meridional. Uma baixa nesta região tinha convergência das correntes e movimento vertical ascendente na região da nuvem vírgula. Estas nuvens ocorrem em associação com baroclinia em alguma parte ou em toda a profundidade da troposfera e, ao mesmo tempo, com instabilidade condicional em uma profundidade substancial. A instabilidade baroclínica úmida parece ser o mecanismo responsável pela geração das perturbações de escala intermediária como nuvem vírgula invertida, que afetam o tempo no sul do Brasil.

Reeder e Smith (1998) acentuaram que infelizmente existe pouca informação detalhada sobre a estrutura dos vórtices de ar frio, e que a dinâmica deste processo não está bem estudada. Informações sobre este processo mostram que o mesmo se forma em um cavado de grande escala, associado com uma corrente de jato de altos níveis, sendo que um número significativo deste processo ocorre próximo da costa antártica. Além disso, eles citam os resultados de Jury e Laing para Cape Town e mencionam, particularmente, como fatores importantes para o desenvolvimento dos vórtices da escala intermediária, a fonte de calor de intensidade moderada no setor quente do vórtice e a existência de uma zona baroclínica nos baixos níveis.

Hallak e Dias (2000) estudaram um caso de vórtice de ar frio associado com nuvem do tipo vírgula, que foi observado sobre o Paraguai e sul do Brasil durante o dia 22 de agosto de 1989. Foi utilizado um modelo de circulação global. A mesma metodologia foi usada nas simulações realizadas com o modelo regional RAMS. Foi constatada convergência de umidade em baixos níveis na retaguarda da frente fria, dentro da massa de ar polar, evidente desde 24 horas antes da máxima manifestação do vórtice, bem como a presença de centros de movimento ascendente em 850 e $700 \mathrm{hPa}$.

O desenvolvimento de uma oclusão instantânea ocorre quando nuvens do tipo vírgula, associadas com um cavado de altos níveis, interage com uma banda da frente polar e finalmente se forma um sistema de nuvens de escala $\lambda$ (Zillman e Price, 1972)

A formação de um ciclone no ar frio sem advecção de ar quente, tendo sido observada somente advecção de ar frio, foi chamada por Bluestein (1993) como "polar low". A escala horizontal do ciclone foi de alguns milhares de quilômetros. Este ciclone estava associado com a liberação de calor latente da superfície oceânica quente e o desenvolvimento de instabilidade. Foi destacado que este tipo de vórtice foi observado sobre o oceano próximo da Groenlândia, no norte do oceano Pacífico e sobre o Mediterrâneo.

De acordo com Zverev, (1968), como foi descrito em Fedorova (1999) e Fedorova e Carvalho (2000), na retaguarda das frentes frias que se deslocam rapidamente, pode formar-se uma frente fria secundária. Estas frentes formam-se no estágio de oclusão do ciclone, localizam-se na retaguarda do ciclone, no cavado bárico e são associadas com pancadas de chuvas em algumas estações.

Sistemas sinóticos que se assemelham às frentes frias secundárias foram descritos por Mullen (1979). Ele encontrou que pequenos ciclones estavam associados à baroclinia profunda 
em toda a troposfera e a uma corrente de jato bem desenvolvida. Também foi encontrada instabilidade condicional nos baixos níveis da troposfera, e no estágio inicial do desenvolvimento destes ciclones, foi observado aquecimento intenso nos níveis mais baixos. A instabilidade baroclínica foi indicada em todos os sistemas analisados. A liberação de calor latente provoca a formação de ondas curtas nesses ciclones oceânicos. Foi observado um desenvolvimento de nuvens $\mathrm{Cb}$ nas regiões com forte giro do vento em altos níveis da atmosfera.

O estudo da localização da convecção intensa no ciclone no estágio maduro, mostrou uma grande freqüência deste processo, na região entre a parte posterior da banda da frente fria e a "cabeça" do vórtice ciclônico (Carr e Millard, 1984). Esta última região de convecção intensa não existe sempre e está associada com a intrusão do ar seco, "dry instrusion". A linha de convecção nesta região está associada com a frente fria em altos níveis.

Browning (1982) apresentou um modelo muito simples que ajuda na interpretação da estrutura e do tempo associado a frentes frias. O modelo é bastante útil para interpretar precipitações e padrões de nuvens observados por radar e satélite.

Todavia, a terminologia relativa a sistemas sinóticos de escala intermediária não está totalmente definida. Como foi citado por Reeder e Smith (1998), são utilizados os seguintes termos: cavados polares, frentes frias em altos níveis, ciclones polares, vírgula invertida e vórtice do ar frio. Neste estudo, as autoras continuam a utilizar o termo frente fria secundária da mesma maneira como descrito em Zverev (1968) e Fedorova e Carvalho (2000). Além disso, como será mostrado posteriormente na descrição do sistema, o vórtice ciclônico não foi observado nas imagens de satélite; por isso, a utilização da terminologia com a palavra "vórtice", neste caso, não identifica adequadamente o processo analisado.

O objetivo deste trabalho é determinar a estrutura e os fenômenos associados a um caso de frente fria secundária que atingiu o Rio Grande do Sul (RS), pois as frentes frias secundárias são pouco estudadas sobre a América do Sul. Além disso, a experiência na previsão do tempo mostra que estas frentes não são detectadas claramente através de modelos numéricos globais, mas que associadas a elas podem ocorrer precipitações intensas e espalhadas. Todos estes fatores fazem com que a previsão do sistema em estudo seja bastante complicada.

\section{METODOLOGIA E DADOS}

Foi elaborado um arquivo especializado de imagens para os dias 12 e 13 julho de 2000, do satélite GOES no canal infravermelho com dados a cada hora UTC e de dados sinóticos, da análise (00 UTC) do modelo do NCEP (National Center For
Environmental Prediction), com os seguintes campos: pressão ao nível médio do mar, altura geopotencial, linhas de correntes e isotacas, temperatura, advecção de temperatura, umidade relativa, divergência de umidade, divergência, movimentos verticais, vorticidade relativa e advecção de vorticidade. Todos os campos, com exceção do campo de pressão, foram analisados nos níveis de 1000, 925, 850, 700, 500, 400, 300, 250, 200 e $150 \mathrm{hPa}$. Além destes campos do NCEP, também se usou o campo de convergência de umidade em $850 \mathrm{hPa}$, do modelo regional do CPTEC/INPE. Gráficos de termógrafo e higrógrafo disponibilizados pela Estação Agroclimatológica da EMBRAPA/UFPel também foram utilizados.

Foram construídas e analisadas seções verticais de vários parâmetros meteorológicos (temperatura, umidade, vorticidade relativa, altura geopotencial e velocidade vertical), na região da nebulosidade observada na imagem de satélite e associada à frente fria secundária. Foi escolhida uma linha que passa atrás da frente fria, na extensão da frente fria secundária (Figura 1a). O corte nessa direção foi escolhido para mostrar as variações dos parâmetros meteorológicos ao longo da frente secundária, e para identificar as mesmas nas extremidades da frente. Nessa linha foram determinados 5 pontos: 3 pontos foram escolhidos nas partes central, leste e oeste da frente fria secundária, e 2 pontos foram selecionados fora da frente, na região da crista. Estes dois últimos pontos foram usados para comparar os valores dos parâmetros meteorológicos na região onde estava localizada a frente, com valores na região sem frente. Foram extraídos dados nos níveis padrões de todos os parâmetros meteorológicos para cada ponto. Utilizando-se estes dados para vários pontos em vários níveis, foram construídas as seções verticais.

Construíram-se, também, seções verticais perpendiculares às frentes frias principal e secundária, para os seguintes parâmetros: umidade relativa, vorticidade relativa e temperatura. Esta construção foi feita da mesma maneira que aquela da seção ao longo da frente secundária. Os pontos utilizados para esta seção estão apresentados na Figura 1a.

Com os dados de radiossondagem fornecidos pelo Aeroporto Salgado Filho, de Porto Alegre, foram elaborados os perfis verticais de temperatura e umidade. Utilizando esses dados e diagramas termodinâmicos foram calculados os índices de instabilidade K (Vasquez, 1994), Showalter (Bluestein, 1993), Totals-totals (Bluestein, 1993), Levantamento (Bluestein, 1993) e Sweat (Djuric, 1994) para verificar-se o comportamento e a instabilidade da atmosfera na região da frente fria secundária.

Por último, utilizando dados de superfície cedidos pelo $8^{\circ}$ Distrito de Meteorologia, foram elaboradas cartas sinóticas sobre o RS. É importante acentuar que no Estado estas cartas não são construídas. Todavia, são importantes para a análise de mesoescala e de processos sinóticos; assim, estas cartas permitem analisar a estrutura da frente fria secundária. 


\section{RESULTADOS}

\subsection{Resultados das Análises das Imagens de Satélites e Diferentes Campos Meteorológicos para a Identificação da Frente Fria Secundária}

\subsubsection{Análise das Imagens de Satélite}

Utilizando-se as seqüências de imagens pode-se concluir que uma banda de nebulosidade começou a se formar no dia 12 de julho, às 10 UTC; no dia seguinte, 13 de julho às 08 UTC, ela estava bem definida. $\mathrm{Na}$ imagem de satélite do dia 13 de julho de 2000 às 00 UTC (Figura 1a), observa-se esta banda de nebulosidade com nuvens do tipo cumulus médios, cumulus congestus e cumulonimbus. Esta banda está localizada a sudeste da América do Sul, na retaguarda da frente fria e foi observada nas imagens de satélite durante, aproximadamente, um dia e meio (33 horas).

Pode-se observar através de todas as imagens de satélites do dia 13 de julho de 2000, que a banda de nebulosidade relacionada à frente secundária, apresenta uma curvatura ciclônica; esta curvatura foi registrada durante, aproximadamente, cinco horas. Já na imagem das 15 UTC (Figura 1b), esta curvatura não está mais pronunciada. É importante acentuar que durante todo este período foi registrada somente uma banda de nebulosidade e que não foi formado um vórtice ciclônico.
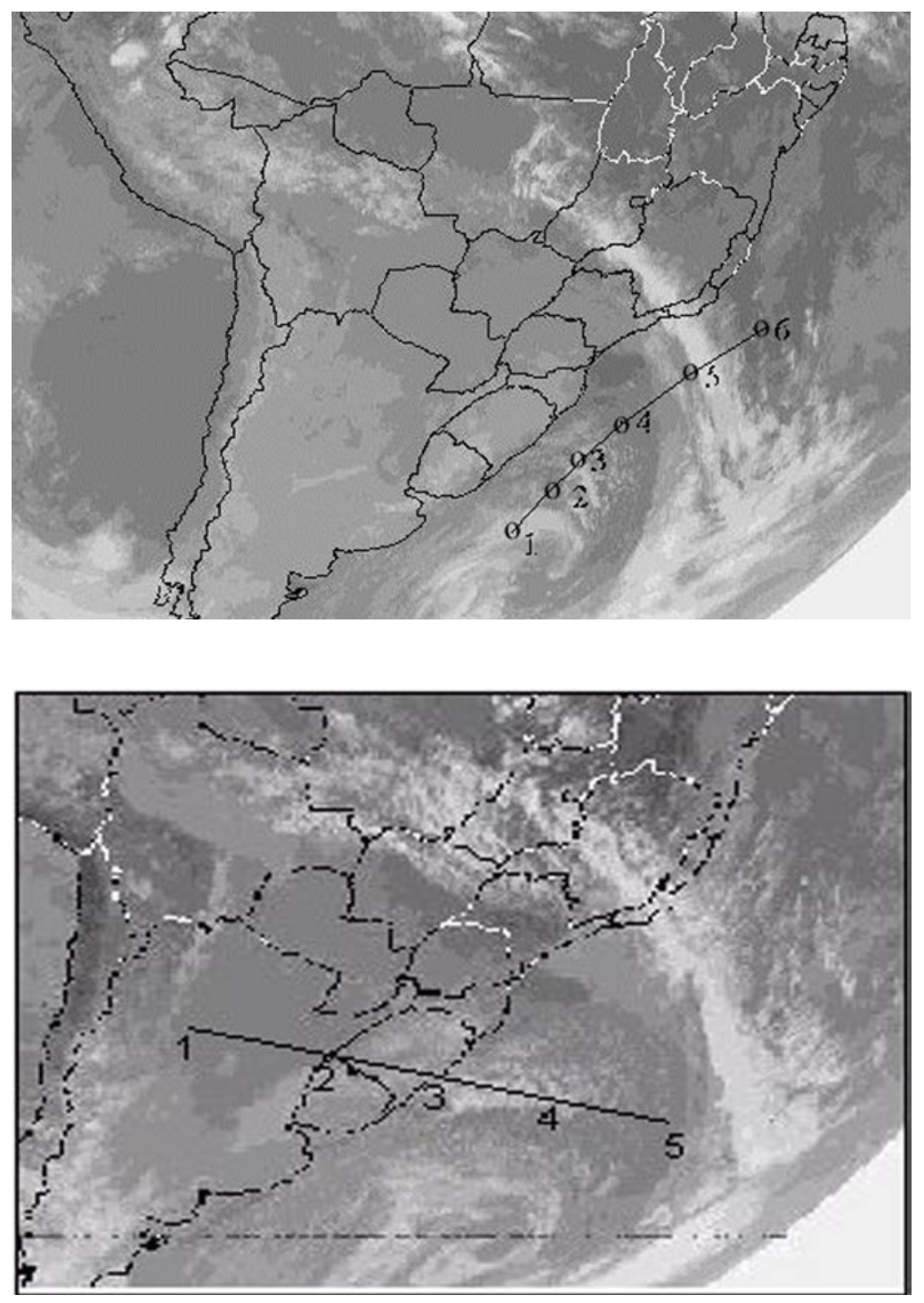

Figura 1 - Imagem de Satélite do dia 12 de julho, as 10 UTC (a) e 13 de julho, as 08 UTC (b) 


\subsubsection{Fenômenos Meteorológicos sobre o RS.}

Os mapas sinóticos (das 18 UTC) sobre o Rio Grande do Sul mostram que nesta região e na retaguarda da frente fria secundária, o céu apresentava-se encoberto com nuvens $\mathrm{St}, \mathrm{Sc}$ e $\mathrm{Cb}$, com chuvas intensas e espalhadas. A visibilidade estava reduzida em algumas estações (era de $2 \mathrm{~km}$ em estações localizadas; na maior parte, estava entre 4 e $10 \mathrm{~km}$.) devido à presença de névoa úmida. As temperaturas apresentavam-se baixas, entre -3 e $5^{\circ} \mathrm{C}$, e houve geadas. Em Passo Fundo, foi registrada a ocorrência de neve (Figura 2).

\subsubsection{Análises dos Campos de Pressão e Altura Geopotencial}

Numa análise geral do campo de pressão reduzida ao nível médio do mar das 00 UTC do dia 12 e também do dia 13 de julho de 2000 sobre a América do Sul (Figura 3), nota-se um cavado bem definido associado à frente fria, e verifica-se que $\mathrm{o}$ mesmo não ocorre sobre a região da frente fria secundária. As cartas sinóticas detalhadas do dia 12 de julho de 2000 do Rio Grande do Sul confirmam a não existência do cavado.

Nos campos de altura geopotencial em 1000, 925 e 850 $\mathrm{hPa}$, pela falta de gradiente, não foi possível identificar a zona frontal. Em níveis médios (Figura 4a), pode-se observar um centro de baixa sobre o oceano Atlântico Sudeste da América do Sul. Em níveis altos (Figura 4b), a zona frontal referente à frente fria principal está bem definida, ou seja, existe um gradiente marcante de altura geopotencial, e devido à inclinação da superfície frontal na direção do ar frio, a zona com estes

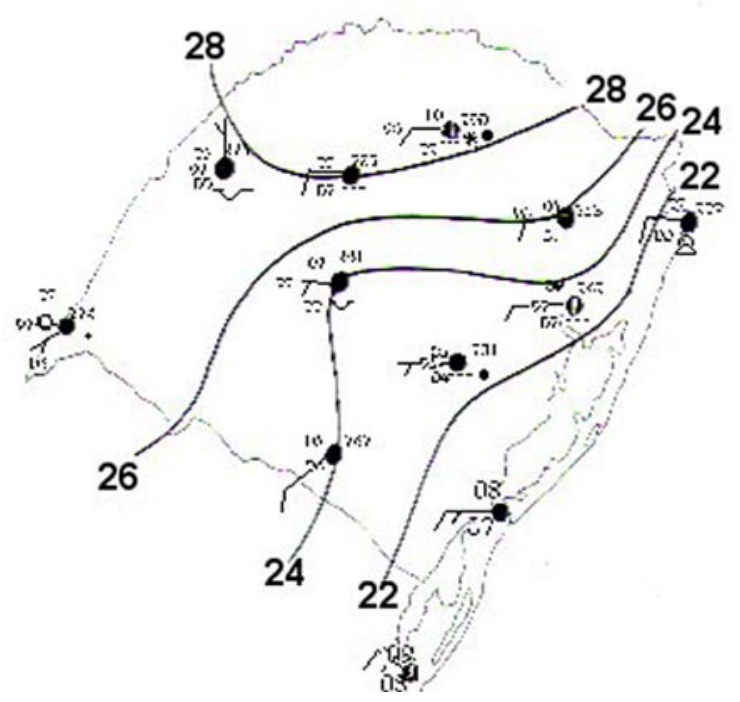

Figura 2 - Carta Sinótica do Rio Grande do Sul (18 UTC) gradientes se localiza nas regiões de Santa Catarina e partes norte e centro do RS. Assim, a frente secundária está sob a zona frontal principal no nível de $250 \mathrm{hPa}$.

\subsubsection{Análises das Cartas de Linhas de Corrente e Corrente de Jato}

No campo de linhas de corrente em $925 \mathrm{hPa}$ (Figura 5a) foi possível observar o deslocamento de ar a partir do sul, provocando a invasão de ar frio. Em níveis médios $(500 \mathrm{hPa})$, o escoamento estava de sudoeste. Já em altos níveis ( $150 \mathrm{hPa})$, o escoamento estava quase zonal na região do RS, ou seja, na frente secundária; todavia na extremidade oeste desta frente a corrente era meridional. A distribuição destas correntes com a altura estava associada com o cavado em todos os níveis da troposfera; o eixo deste cavado estava inclinado para oeste com o aumento da altura.

A frente fria secundária estava localizada na retaguarda da corrente de jato no nível de $300 \mathrm{hPa}$ (Figura 5b), na entrada no núcleo da mesma corrente neste nível e no lado frio da zona frontal em altos níveis. No nível de $300 \mathrm{hPa}$ foram observados os maiores valores de velocidade do vento, os quais atingiram $65 \mathrm{~m} / \mathrm{s}$ no núcleo da corrente de jato.

\subsubsection{Análises dos Campos de Temperatura, Umidade Relativa e Divergência de Umidade}

No campo de temperatura à superfície, observa-se a presença de ar muito frio (temperatura menor do que $-3^{\circ} \mathrm{C}$ ), no estado de Santa Catarina (Figura 6a). Em 925 hPa observa-se um

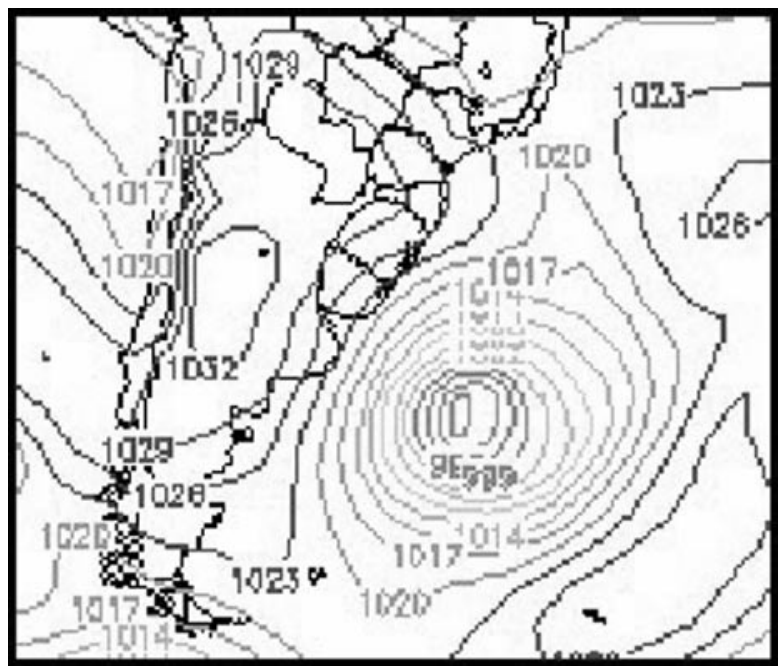

Figura 3 - Campo de pressão reduzida ao nível médio do mar (00 UTC) 
núcleo de ar frio com valor mínimo de $0{ }^{\circ} \mathrm{C}$ sobre a parte norte do estado do RS e o oeste de Santa Catarina (Figura 6b). Em níveis médios é possível observar uma onda de ar frio na região da frente fria secundária. Esta onda de ar frio pode ser identificada até $300 \mathrm{hPa}$. Em $250 \mathrm{hPa}$, ao longo da nebulosidade da frente fria secundária, observa-se um língua de ar relativamente quente apresentando um núcleo fechado com temperatura de aproximadamente $43^{\circ} \mathrm{C}$ negativos. É interessante notar que em Pelotas, no mês de julho, as temperaturas médias são, freqüentemente, mais altas, ou seja, os valores de temperatura média das mínimas e média das máximas são $8,6{ }^{\circ} \mathrm{C}$ e17, $6{ }^{\circ} \mathrm{C}$, respectivamente.

A análise dos campos sinóticos sobre o RS nos dias 12 e 13 de julho para os horários 00, 12 e 18 UTC (foram construídos seis mapas), mostram que em todas as estações meteorológicas do Estado RS houve queda de temperatura. Esta queda variou entre $2{ }^{\circ} \mathrm{C}$ (Cruz Alta, Santa Vitória do Palmar e Santa Maria) e $7{ }^{\circ} \mathrm{C}$ (Torres), num período de 36 horas.

A queda de temperatura também foi confirmada por dados de termógrafo (figura 7) para Pelotas: do dia 10 até o dia 13 foi observada queda de temperatura com amplitudes diárias pequenas e temperatura mínima de $3^{\circ} \mathrm{C}$, na madrugada (entre 4 e 8 horas local) do dia 14 de julho. No dia seguinte, a amplitude de temperatura já atingiu $9{ }^{\circ} \mathrm{C}$. No mesmo período de tempo ocorreu uma variação brusca da umidade relativa (Figura 8), ou seja, nos dias 10 a 13 a umidade relativa (UR) estava alta (entre 80 e 98\%) durante todo o dia; todavia, nos dias 14 e 15 a variação diária de UR esteve entre 46 e 95\%. Todos estes dados mostram que da noite do dia 13 para o dia 14 ocorreu uma mudança da massa de ar.

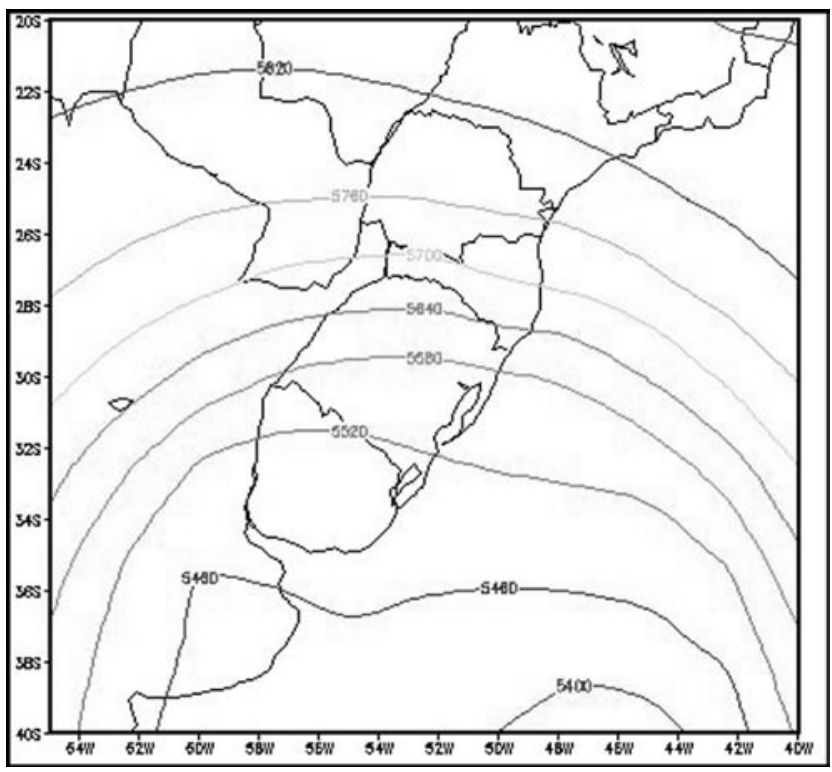

Os mapas de umidade nos baixos níveis até $850 \mathrm{hPa}$ mostram claramente o comportamento da frente fria secundária com a umidade relativa bastante elevada (90\%), ao longo da frente fria secundária (Figura 9). Já no nível de $700 \mathrm{hPa}$ a faixa de ar mais úmido (com umidade relativa de 60 até $80 \%$ ) se localiza ao sul do RS, ou seja, ao sul da faixa de nebulosidade da frente fria secundária. Nos níveis mais altos (500, 400 e 300 $\mathrm{hPa}$ ) o ar úmido estava ao sul, no extremo sul do Brasil e na parte leste do Uruguai. Nestes níveis ao longo da frente fria secundária o ar estava muito seco, a umidade relativa variava de 10 a $20 \%$.

\subsubsection{Análises dos Campos de Divergência e Vorticidade}

$\mathrm{Na}$ região da frente fria secundária em baixos níveis observam-se valores positivos de divergência $\left(6,0 \times 10^{-6} \mathrm{~s}^{-1}\right.$, no nível de $1000 \mathrm{hPa}$ ). Na retaguarda da frente fria secundária, em 1000 e $700 \mathrm{hPa}$, observam-se núcleos fechados de divergência em torno de $-3,0 \times 10^{-6}$ e de $-2,0 \times 10^{-6} \mathrm{~s}^{-1}$, conforme pode ser visto na Figura 10a, que mostra a carta de divergência para 700 $\mathrm{hPa}$. Já em níveis médios, encontrou-se convergência $\left(-5,0 \times 10^{-6}\right.$ $\mathrm{s}^{-1}$, no nível de $\left.500 \mathrm{hPa}\right)$ com seu núcleo $\left(-8,0 \times 10^{-6} \mathrm{~s}^{-1}\right.$, neste nível) localizado na vanguarda desta frente. Em altos níveis (300 e $250 \mathrm{hPa}$ ), na região da frente, os valores de divergência são próximos de zero. Comparando os valores de divergência encontrados na região da frente secundária com os valores da mesma na nebulosidade ciclogenética (Fedorova et al., 1999, onde os valores médios máximos foram $+4,0 \times 10^{-5} \mathrm{~s}^{-} 1$, no nível de $250 \mathrm{hPa}$ ) e no centro da Alta da Bolívia (Virji, 1981, com valores máximos $+30,0 \times 10^{-6} \mathrm{~s}^{-1}$ ) pode ser concluído que estes

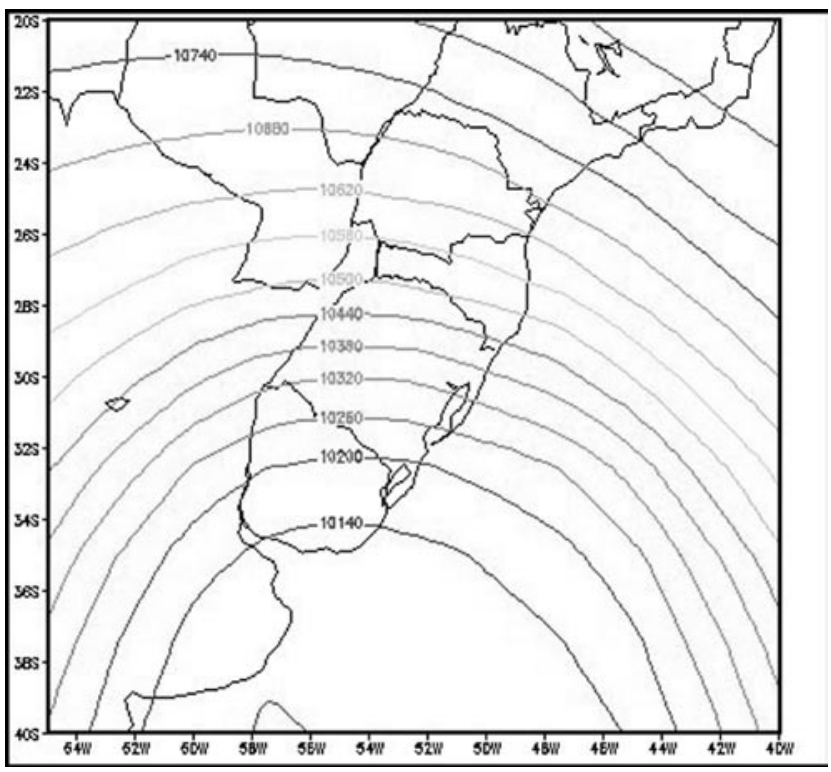

Figura 4 - Campo de altura geopotencial: níveis médios (a) e níveis altos (b) 
valores na frente fria secundária não foram significativos.

No campo de vorticidade relativa em baixos níveis na região da frente fria secundária, observam-se valores positivos de vorticidade relativa $\left(2,0 \times 10^{-5} \mathrm{~s}^{-1}\right)$. Em médios e altos níveis os valores são negativos $\left(-4,0 \times 10^{-5} \mathrm{~s}^{-1}\right)$ (Figura 10b). Signorini et al.(1998b) encontraram valores positivos em baixos níveis e negativos em altos na frente oclusa. No nível de 500 $\mathrm{hPa}$ é observada uma faixa com valores negativos ao longo da nebulosidade da frente secundária. Para efeito de comparação, apresentam-se os valores de vorticidade relativa na região da nebulosidade ciclogenética: na retaguarda, $-0,0001 \mathrm{~s}^{-1}$, e na vanguarda, $+10,0 \times 10^{-5} \mathrm{~s}^{-1}$ (Fedorova e Carvalho, 1999). De acordo com Virji (1981), no centro da Alta da Bolívia o valor extremo de vorticidade relativa ciclônica foi $10,0 \times 10^{-6} \mathrm{~s}^{-1}$.

O campo de advecção de vorticidade no nível de 850 $\mathrm{hPa}$ não se apresentava bem definido, com valores em torno de $-2,0 \times 10^{-10} \mathrm{~s}^{-1}$; já no nível de $700 \mathrm{hPa}$ aparecem dois núcleos, os quais estão claramente definidos. No nível de $500 \mathrm{hPa}$ foram observados valores positivos $\left(+3,0 \times 10^{-9} \mathrm{~s}^{-1}\right)$ ao longo da frente fria secundária e valores negativos $\left(-3,0 \times 10^{-9} \mathrm{~s}^{-1}\right)$ na retaguarda da mesma; isto significa que as ondas curtas intensificaram-se nos níveis de 700 e $500 \mathrm{hPa}$.

\subsection{Resultados da Análise dos Perfis Verticais de Temperatura e Umidade.}

A análise da distribuição vertical da umidade mostra que a camada em baixos níveis, até $700 \mathrm{hPa}$, estava bastante úmida. No restante da atmosfera, a distribuição vertical de temperatura e de temperatura do ponto de orvalho indica que a diferença

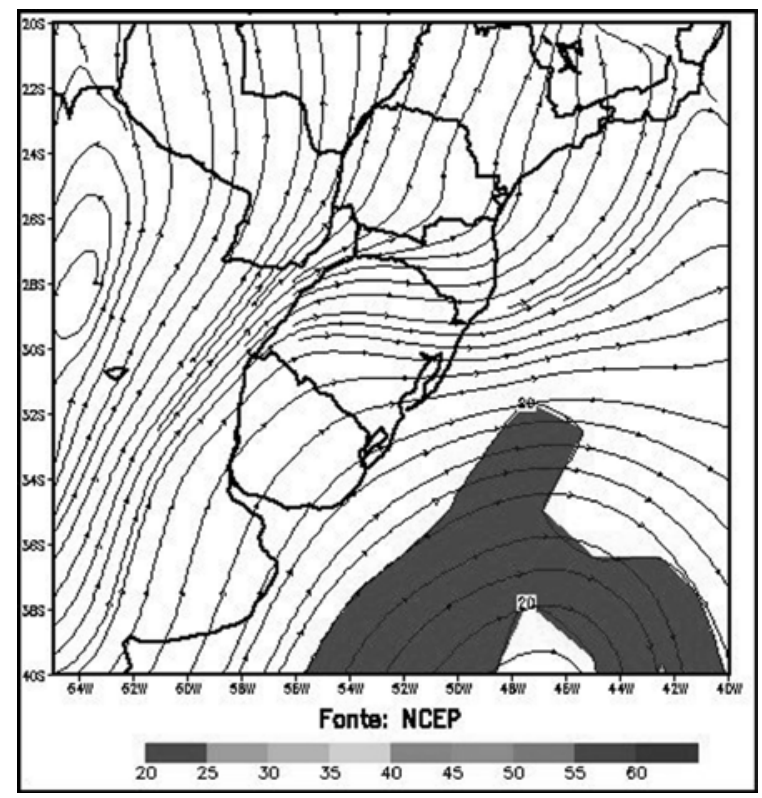

Figura 5 - Campo de linhas de correntes $925 \mathrm{hPa}$ (a) e $300 \mathrm{hPa}$ (b) entre estas duas temperaturas era de, aproximadamente, $10^{\circ} \mathrm{C}$, o que significa que a atmosfera estava bastante seca, ou seja, foi observada uma intrusão de ar seco (Figura 11).

A atmosfera estava instável da superfície até $900 \mathrm{hPa}$ e condicionalmente instável até $700 \mathrm{hPa}$. A camada adiabática, a qual se forma em conseqüência da turbulência (Djuric, 1994, p. 76), estava entre os níveis de 850 e $700 \mathrm{hPa}$. No dia 13 de julho, entre os níveis de 620 e $580 \mathrm{hPa}$ foi observada uma isotermia e entre os níveis de 580 e $560 \mathrm{hPa}$ existia uma inversão de temperatura, resultante de subsidência.

O nível de condensação por levantamento foi localizado em $930 \mathrm{hPa}$. Somente em baixos níveis foi observada uma camada de CAPE (convective available potential energy, Dusan, 1995) positiva com valores muito pequenos $\left(9,57 \mathrm{~J} \mathrm{~s}^{-1}\right)$. A base da tropopausa estava no nível de $300 \mathrm{hPa}$, ou seja, no mesmo nível que na frente oclusa (Signorini et al., 1998a). No mesmo trabalho foi encontrado que o nível da tropopausa na frente fria estava mais alto, $200 \mathrm{hPa}$.

De acordo com o Manual (1986, p. 392-393), as precipitações se apresentam na forma de neve quando a altura da isoterma de $0^{\circ} \mathrm{C}$ for menor ou igual a $500 \mathrm{~m}$, e a temperatura à superfície for menor ou igual a $3^{\circ} \mathrm{C}$. Além disso, se a topografia relativa da camada $1000-850 \mathrm{hPa}$ (TR $1000-850$ ) for menor do que 128 dam, é observada neve; se $128 \leq \mathrm{TR}_{1000-850} \leq 132$ dam, é observada neve com chuva. Os valores de TR 1000-850 maiores que 132 estão associados com chuva. $\mathrm{O}$ diagrama para o dia 13 mostra que a altura da isoterma de $0^{\circ} \mathrm{C}$ é baixa, aproximadamente, $950 \mathrm{hPa}$ e a altura deste nível era $840 \mathrm{gpm}$ (pelo mapa e diagrama). Os valores de TR ${ }_{1000-850}$ para todo o Estado foram 132 dam. Por isso, pode-se concluir sobre houve

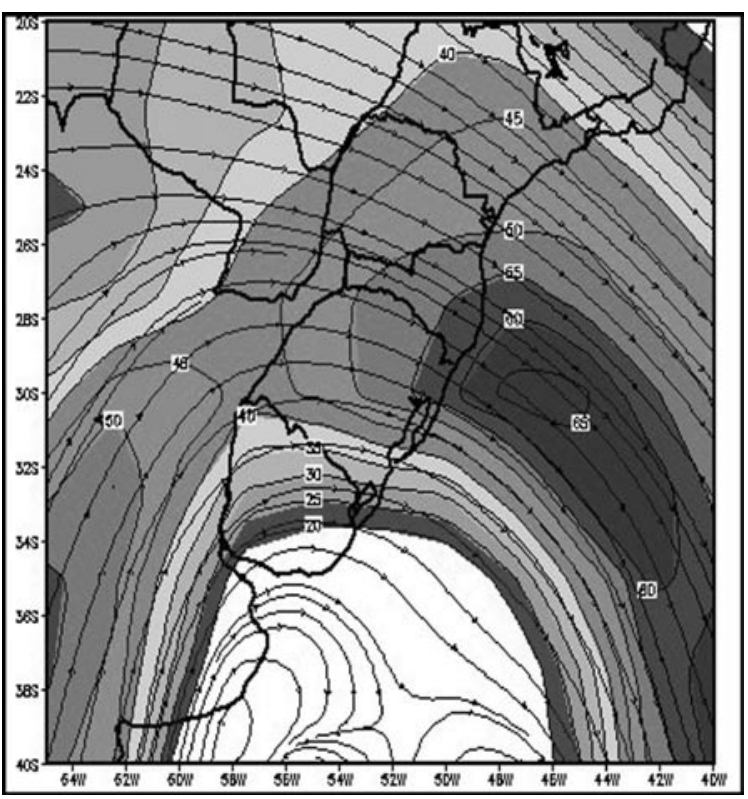


possibilidade de neve com chuva neste dia. Além disso, acima do nível da isoterma de $0^{\circ} \mathrm{C}$, estão localizadas camadas com ar úmido nos níveis de 900 e $700 \mathrm{hPa}$. Esta posição das camadas úmidas acima do nível da isoterma $0^{\circ} \mathrm{C}$, mostra a possibilidade de precipitações do tipo pelotas de gelo ou granizo misturado com chuva ou neve (Dusan, 1995; p. 77).

Os resultados do cálculo dos índices de instabilidade estão apresentados na Tabela 1. A atmosfera apresentava-se condicionalmente instável até $700 \mathrm{hPa}$; no restante, apresentavase estável. A maioria dos índices de instabilidade não mostrou instabilidade da atmosfera e precipitações intensas. Somente

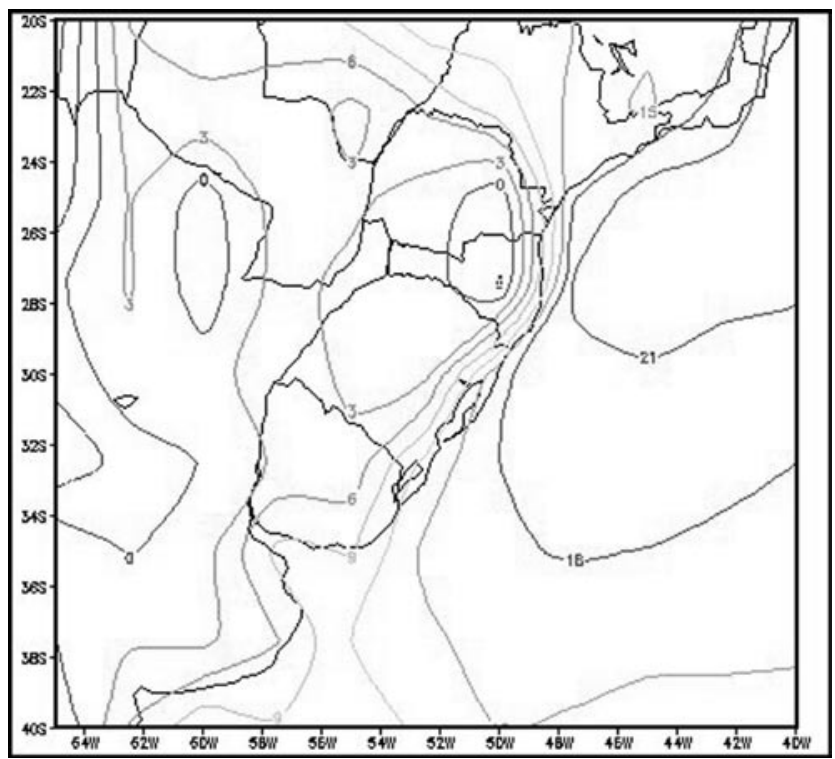

o índice K, para o dia 13 de julho, detectou a possibilidade de desenvolvimento de $\mathrm{Cb}$ esparsos.

\subsection{Resultados da Análise das Seções Verticais da Atmosfera}

\subsubsection{Análise da Distribuição Vertical da Umidade}

A análise da seção vertical de umidade (Figura 12a) mostra que na região da frente fria secundária (pontos 3 e 4), a umidade estava bastante elevada entre os níveis de 925 e 850 $\mathrm{hPa}$, com valor em torno de $90 \%$. Em níveis médios foi possível

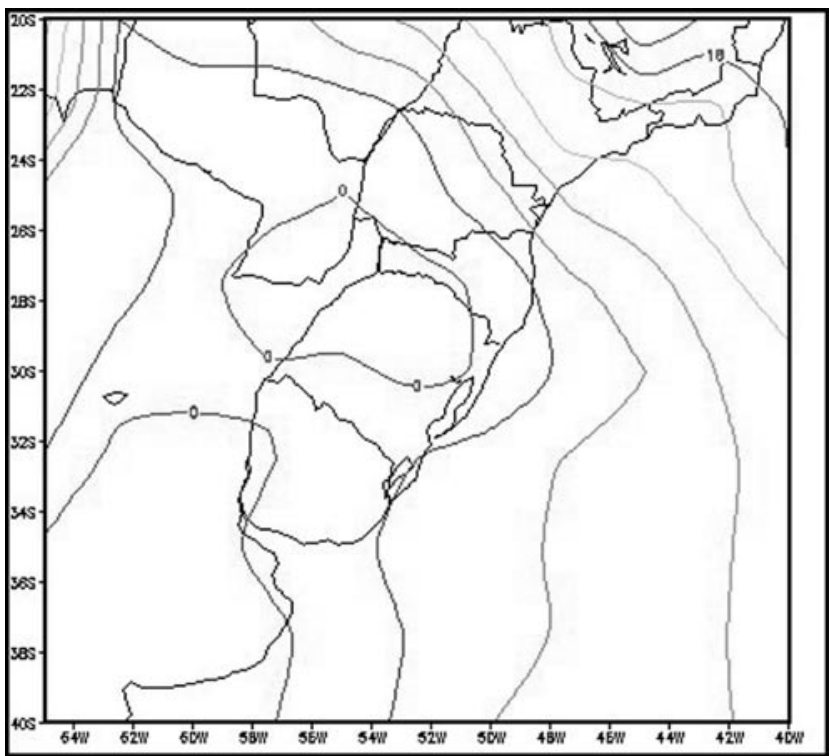

Figura 6 - Campo de temperatura à superfície (a) e $925 \mathrm{hPa}$ (b).

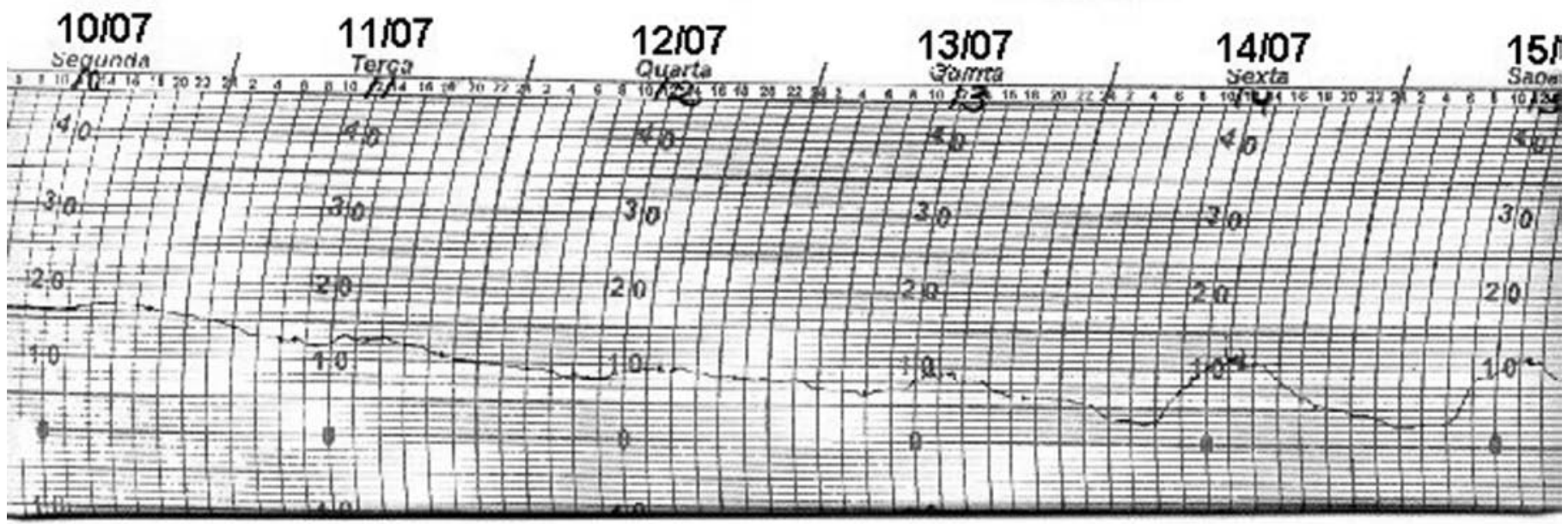

Figura 7 - Temperatura do ar para Pelotas: 10 a 13 de julho 
observar um núcleo de umidade fechado com valor de $70 \%$.

No prolongamento da frente fria secundária na direção leste (ponto 5), a umidade em baixos níveis também estava bastante elevada com seu valor máximo no nível de $850 \mathrm{hPa}$, chegando a $80 \%$. Em níveis médios a atmosfera estava mais seca, com a umidade relativa próxima a $25 \%$.

No prolongamento da frente fria secundária na direção oeste (ponto 1), a umidade estava mais baixa que nas outras regiões, aproximadamente 40 e $50 \%$; no ponto 2 , estava mais elevada, aproximadamente, $85 \%$. Já em níveis médios, a atmosfera estava muita seca com a umidade variando entre 15 e $25 \%$.

A análise da seção perpendicular às frentes (Figura 12b) mostra a umidade em baixos níveis mais elevada (aproximadamente 90\%), nas regiões das frentes secundária, oclusa e entre estas frentes. Nos níveis médios, nas mesmas regiões, a umidade cai até $40 \%$ e em altos níveis aumenta novamente somente na frente oclusa. Um núcleo de ar mais seco (com 10\% de umidade relativa) localiza-se em níveis médios na retaguarda da frente fria e na vanguarda da frente secundária.

\subsubsection{Análise da Distribuição Vertical da Temperatura}

A seção vertical de temperatura (Figura 13a) mostra que na região da frente fria secundária (pontos 3 e 4 ), havia isolinhas de temperatura com inclinação entre os níveis de 925 e $300 \mathrm{hPa}$. No nível de $250 \mathrm{hPa}$, é possível observar um núcleo de ar frio nesta região e uma língua de ar frio a partir deste núcleo, que atingiu o nível de $700 \mathrm{hPa}$. Os valores nos pontos
3 e 4 , no nível de $700 \mathrm{hPa}$ são, respectivamente, -11 e $-7,5^{\circ} \mathrm{C}$. No prolongamento da frente fria secundária na direção oeste (leste) as temperaturas à superfície foram mais baixas (altas) do que nesta frente.

A seção transversal de temperatura perpendicular às frentes (Figura 13b) apresenta a inclinação da frente fria desde a superfície (próximo do ponto 5) até altos níveis, onde ela está localizada sobre a frente secundária. Na região da frente secundária em baixos níveis pode ser vista uma fraca inclinação das isotermas.

\subsubsection{Análise da Distribuição Vertical da Vorticidade Relativa}

$\mathrm{Na}$ seção vertical de vorticidade relativa (Figura 12c) observa-se, que em superfície, entre os pontos 2 e 4, existem valores de vorticidade ciclônica em torno de $-5 \times 10^{-5} \mathrm{~s}^{-1}$. No prolongamento da frente fria secundária na direção oeste (ponto 1), há valores positivos de vorticidade relativa, porém muito pequenos. No prolongamento da frente fria secundária na direção leste (ponto 5), notam-se valores positivos nos níveis de 1000 e $925 \mathrm{hPa}$; já em $850 \mathrm{hPa}$ a vorticidade apresenta valor negativo. Os maiores valores de vorticidade ciclônica (em torno de $-9 \times 10^{-5} \mathrm{~s}^{-1}$ ) foram observados na região da frente fria secundária (pontos 3 e 4), entre os níveis de 300 e $200 \mathrm{hPa}$.

A seção vertical de vorticidade relativa perpendicular a ambas as frentes (Figura 13c) mostra um núcleo grande de valores negativos (até $-9 \times 10^{-5} \mathrm{~s}^{-1}$ ) em altos níveis da troposfera na região da frente secundária. Em baixos níveis, valores negativos foram observados na região da frente oclusa (ponto 1) e da frente fria (ponto 5). Na região da frente secundária, na

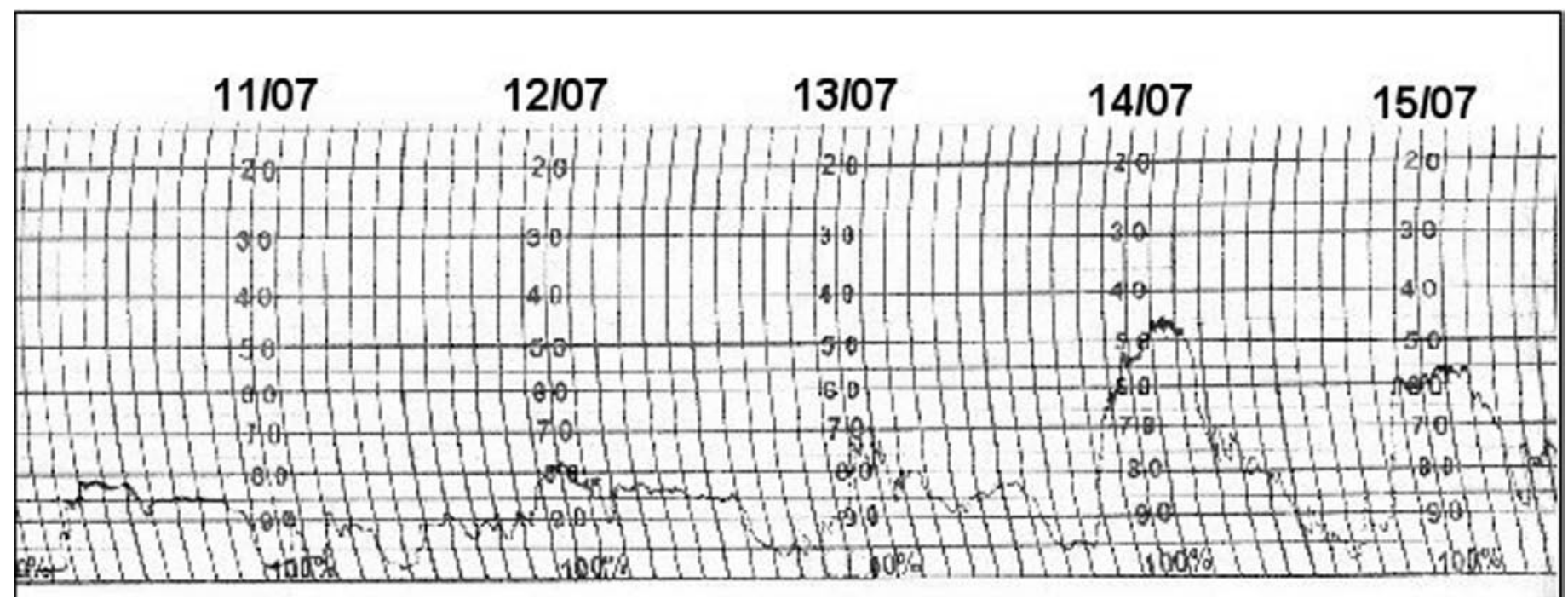

Figura 8 - Temperatura do ar para Pelotas: 10 a 13 de julho 
retaguarda e vanguarda da mesma, os valores de vorticidade relativa em baixos níveis foram positivos.

\subsection{Discussão}

A semelhança entre a frente secundária e os outros sistemas de escala intermediária, citados neste trabalho, é que

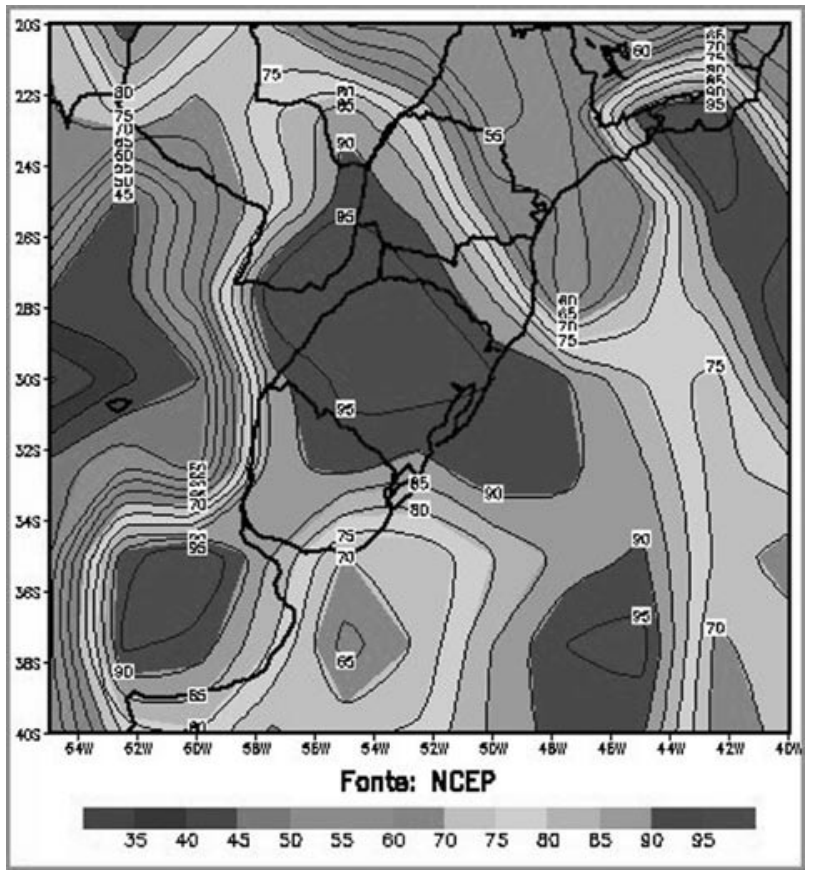

Figura 9 - Campos de umidade relativa (\%) em $850 \mathrm{hPa}$.
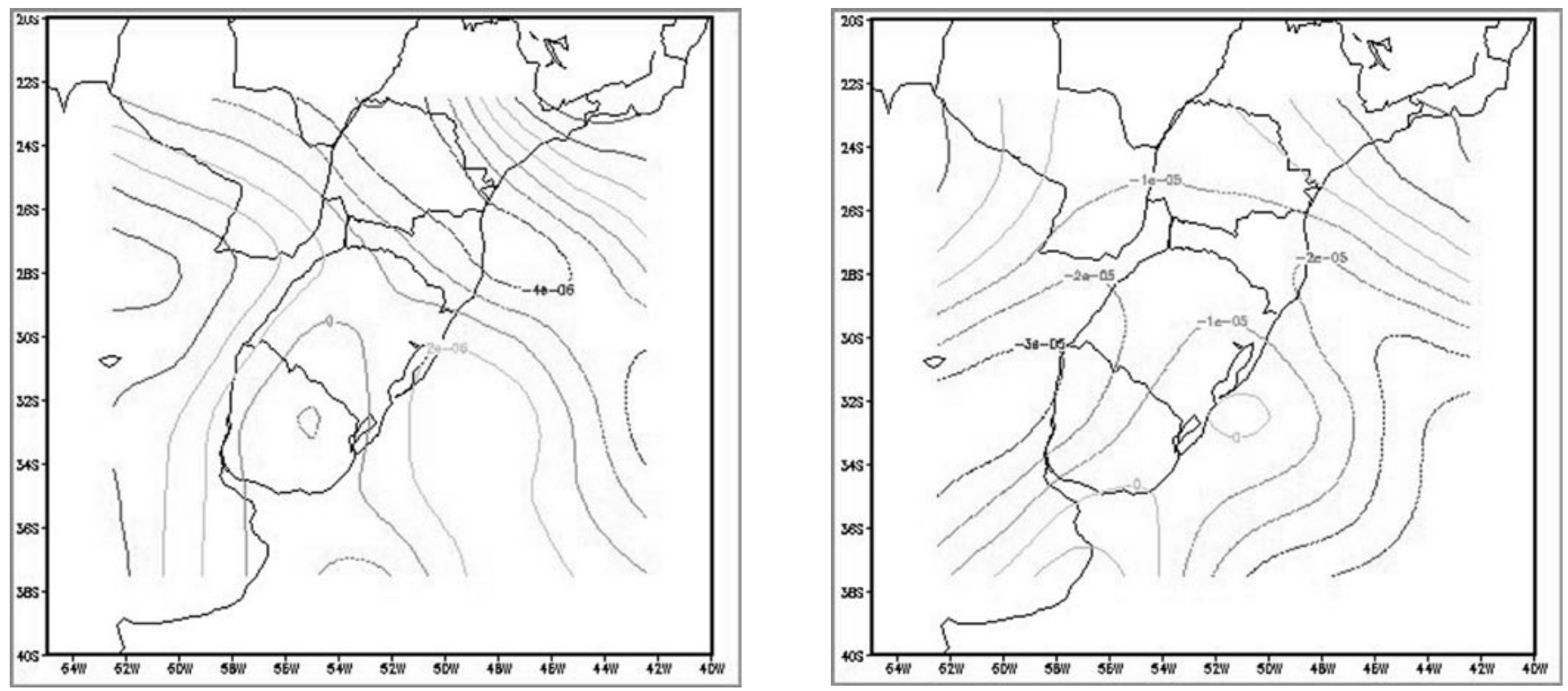

uma corrente de jato bem desenvolvida acompanhou todos estes sistemas e eles se desenvolveram no lado polar desta corrente (Mullen, 1979; Reed, 1979; Reeder e Smith, 1998).

A instabilidade condicional em uma profundidade substancial (Bonatti, 1988), ou nos baixos níveis da troposfera (Mullen, 1979), ou até de $500 \mathrm{hPa}$ (Reed, 1979), é típica para os pequenos ciclones. Na frente secundária a instabilidade atmosférica era semelhante, ou seja, o ar estava instável da superfície até $900 \mathrm{hPa}$ e condicionalmente instável até $700 \mathrm{hPa}$.

No caso da frente secundária, nas imagens de satélite não foi observada a formação de um vórtice; todavia, os vórtices foram descritos em estudos sobre sistemas sinóticos na escala intermediária (por exemplo, vórtice de ar frio). Além disso, o sistema de nuvem do tipo vírgula estudado por Bonatti (1988), estava associado com uma baixa relativamente quente observada na carta de pressão à superfície, e o outro estudado por Reeder e Smith (1998) estava associado a um cavado de grande escala, os quais não foram registrados no caso da frente secundária. A divergência nos baixos níveis e a vorticidade anticiclônica mostram, que a frente secundária não aparece na forma tradicional das frentes, ou seja, com um cavado em baixos níveis bem definido, com vorticidade ciclônica e com a convergência das correntes. Estes fatos complicam a previsão desta frente.

Os mecanismos de formação de nuvens vírgula invertida (Bonatti, 1988) parecem ser diferentes daqueles descritos no presente trabalho. Entre as diferenças, pode ser acentuada uma faixa de vento de norte, que transporta calor e umidade (esteira transportadora quente), a qual foi típica para a nuvem vírgula e não foi observada no caso analisado neste estudo.

Figura 10 - Campo de divergência $700 \mathrm{hPa}$ (a) e vorticidade relativa (b) 
Aquecimento intenso abaixo e liberação de calor latente para a formação de ondas curtas em ciclones oceânicos, foram observados para os casos de Reed (1979), Mullen (1979) e Bonatti (1988). Reeder e Smith (1998) encontraram uma fonte de calor de intensidade moderada no setor quente do vórtice. Estes ciclones foram observados, freqüentemente, no inverno sobre os oceanos; somente foi acentuada uma preferência para as estações de transição. $\mathrm{O}$ caso da frente secundária também ocorreu no inverno, no oceano, mas, além disso, foi registrado sobre todo o estado do Rio Grande do Sul.
A velocidade de deslocamento das frentes fria e secundária ao longo da costa brasileira na direção nordeste durante o dia 13 foi 4,4 e 2,5 m/s, respectivamente, ou seja, muito pequena. $\mathrm{O}$ sistema de nuvem vírgula, o qual foi analisado por Bonatti (1988), deslocou-se mais rápido do que o processo analisado, com velocidade de $8 \mathrm{~m} / \mathrm{s}$.

No caso analisado neste trabalho, a maioria dos índices de instabilidade não mostrou possibilidade de convecção. Somente o índice $\mathrm{K}$ detectou a possibilidade de desenvolvimento de Cb's esparsos. Na opinião das autoras, isto ocorreu porque os dados

Tabela 1 - Índices de Estabilidade Atmosférica para o dia 30 de junho de 1998.

\begin{tabular}{|c|c|c|c|}
\hline $\begin{array}{c}\text { Localidade/ } \\
\text { Horário }\end{array}$ & $\begin{array}{c}\text { Showalter } \\
\text { (IS) }\end{array}$ & $\mathrm{K}$ & $\begin{array}{c}\text { Totals } \\
\text { (TOT) }\end{array}$ \\
\hline Torres (0000) & 4,0 & 27,5 & 44,0 \\
Torres (1200) & 3,7 & 28,5 & 44,0 \\
$\begin{array}{c}\text { Porto Alegre } \\
(1200)\end{array}$ & 3,5 & 30,2 & 43,7 \\
$\begin{array}{c}\text { Sta. Vitória do } \\
\text { Palmar (0000) }\end{array}$ & $-0,5$ & 34,4 & 50,6 \\
\hline
\end{tabular}

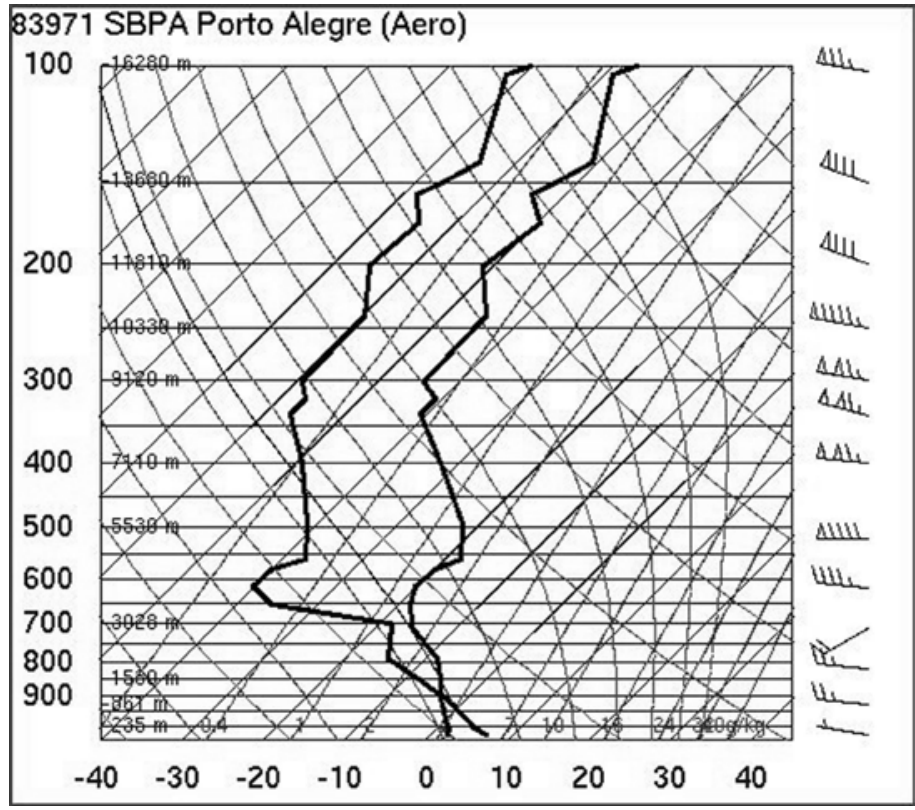

Figura 11 - Diagrama termodinâmico 
de radiossondagem existem somente em uma estação (Porto Alegre), mas a estrutura da frente secundária não era homogênea (como pode ser visto nas imagens de satélite). Por este motivo, o desenvolvimento de instabilidade é difícil de ser detectado usando-se dados de radiossondagem de uma estação somente.

Além disso, provavelmente, próximo de Porto Alegre houve algumas condições específicas, porque os mapas de movimentos verticais em todos os níveis mostraram valores próximos de zero em todas as regiões do RS, e somente próximo de Porto Alegre foi registrado um núcleo com movimentos descendentes, da superfície até $850 \mathrm{hPa}$. No caso da nuvem vírgula (Bonatti, 1988), foram observados movimentos verticais ascendentes. Por outro lado, a frente fria do tipo catafrente, apresenta movimentos descendentes em médios e altos níveis e atrás da linha superficial da mesma (Browning, 1999); nesta frente os movimentos ascendentes ocorreram somente em baixos níveis, na vanguarda da frente à superfície.

Os movimentos descendentes, tanto na frente secundária, quanto na frente "split" (Djuric, 1994), provocam a formação de inversão de subsidência. Todavia, abaixo desta inversão na frente secundária não foi observada uma corrente de jato de baixos níveis e nem uma faixa transportadora quente, as quais são típicas da frente "split". Durante a passagem desta última frente, relativamente ao observador na superfície, primeiramente passa a frente em altos níveis e depois em baixos níveis. No caso da frente secundária, em altos níveis localiza-se a frente

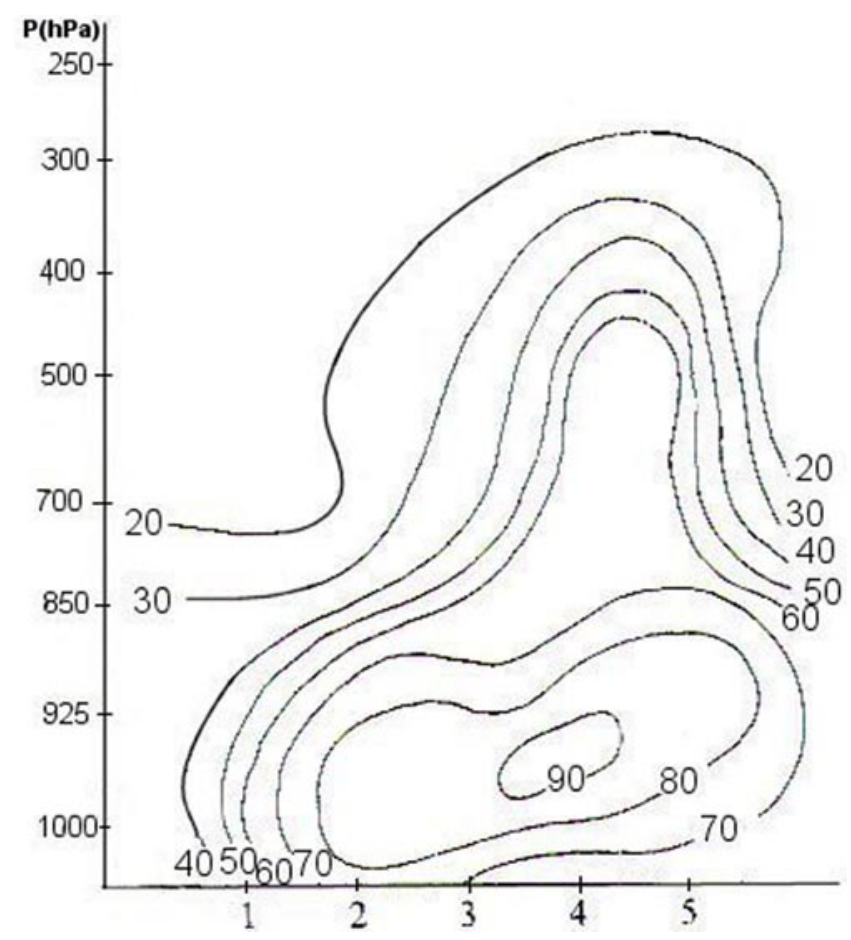

fria principal devido à inclinação da superfície frontal, ou seja, relativamente ao observador na superfície as frentes em baixos e altos níveis passam quase ao mesmo tempo.

No caso analisado no presente estudo, não foram registradas ondas curtas nos baixos níveis da troposfera, mas elas aparecem claramente no nível de $500 \mathrm{hPa}$. A vorticidade relativa neste nível e/ou no nível de $700 \mathrm{hPa}$ (Vasquez, 1994, p.46) é o melhor indicador das ondas curtas (com amplitudes médias de 100 até 1000 milhas). Na frente secundária, no mesmo nível foi observada uma advecção positiva de vorticidade, a qual está associada com convergência das correntes, movimentos verticais e, enfim, (Vasquez, 1994, p.52) com a nebulosidade e as precipitações.

A distribuição vertical da temperatura para o desenvolvimento de convecção intensa na região da intrusão de ar seco, "dry instrusion", mostrou claramente a região desta intrusão em níveis médios e altos, a partir de $600 \mathrm{hPa}$ (Carr e Millard, 1984). No caso analisado neste estudo, também foi registrada uma intrusão de ar seco acima de $700 \mathrm{hPa}$, mas na parte inferior desta camada seca foi observada uma inversão de subsidência na curva de temperatura. Todavia, para os casos de Carr e Millard, ao contrário, um pouco abaixo da camada de intrusão de ar seco, o ar estava instável.

Os pequenos ciclones estudados por Mullen (1979) estavam associados com baroclinia profunda em toda a troposfera. A baroclinia em alguma parte ou em toda a profundidade da

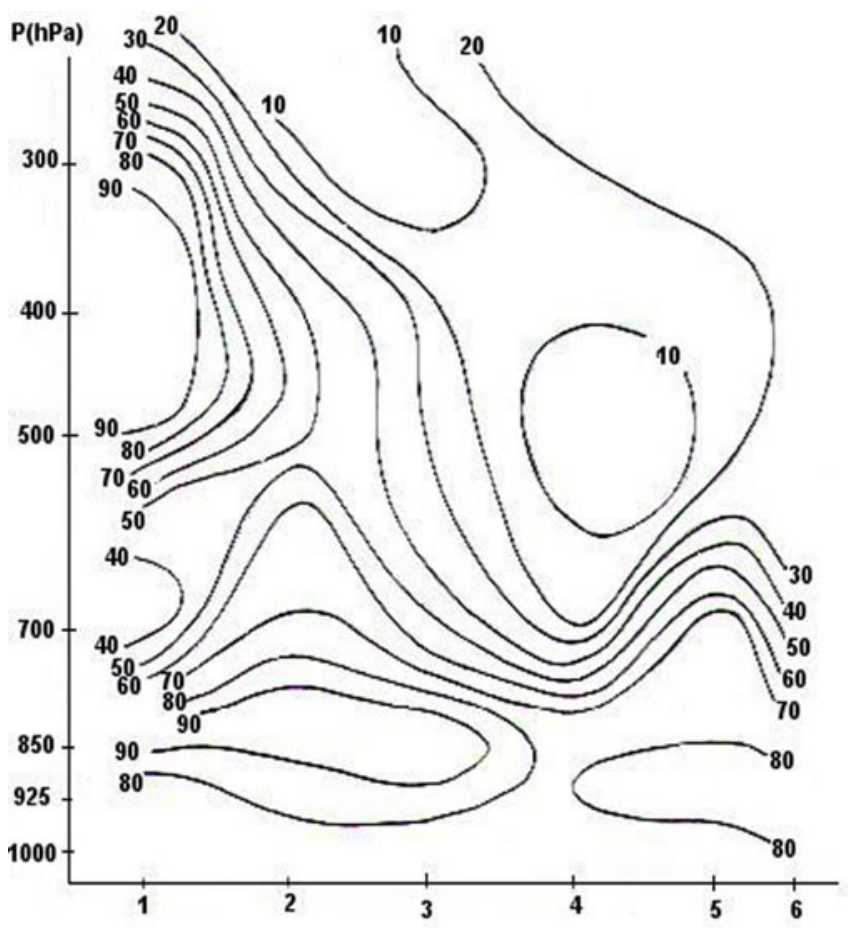

Figura 12 - Seção vertical da umidade do ar (a) e perpendicular às frentes (b) 

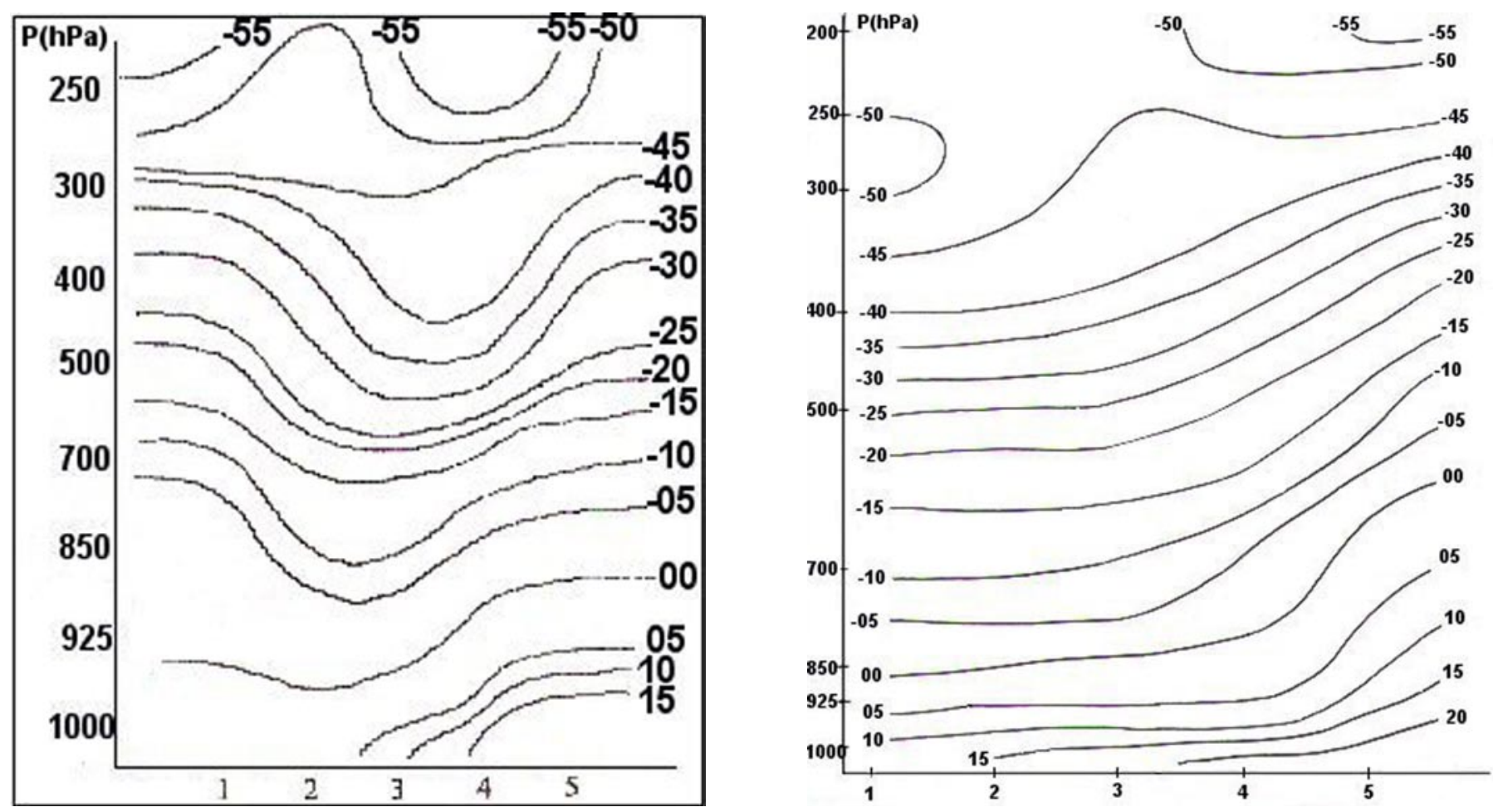

Figura 13 - Seção vertical da temperatura do ar (a) e Seção transversal da temperatura do ar (b)
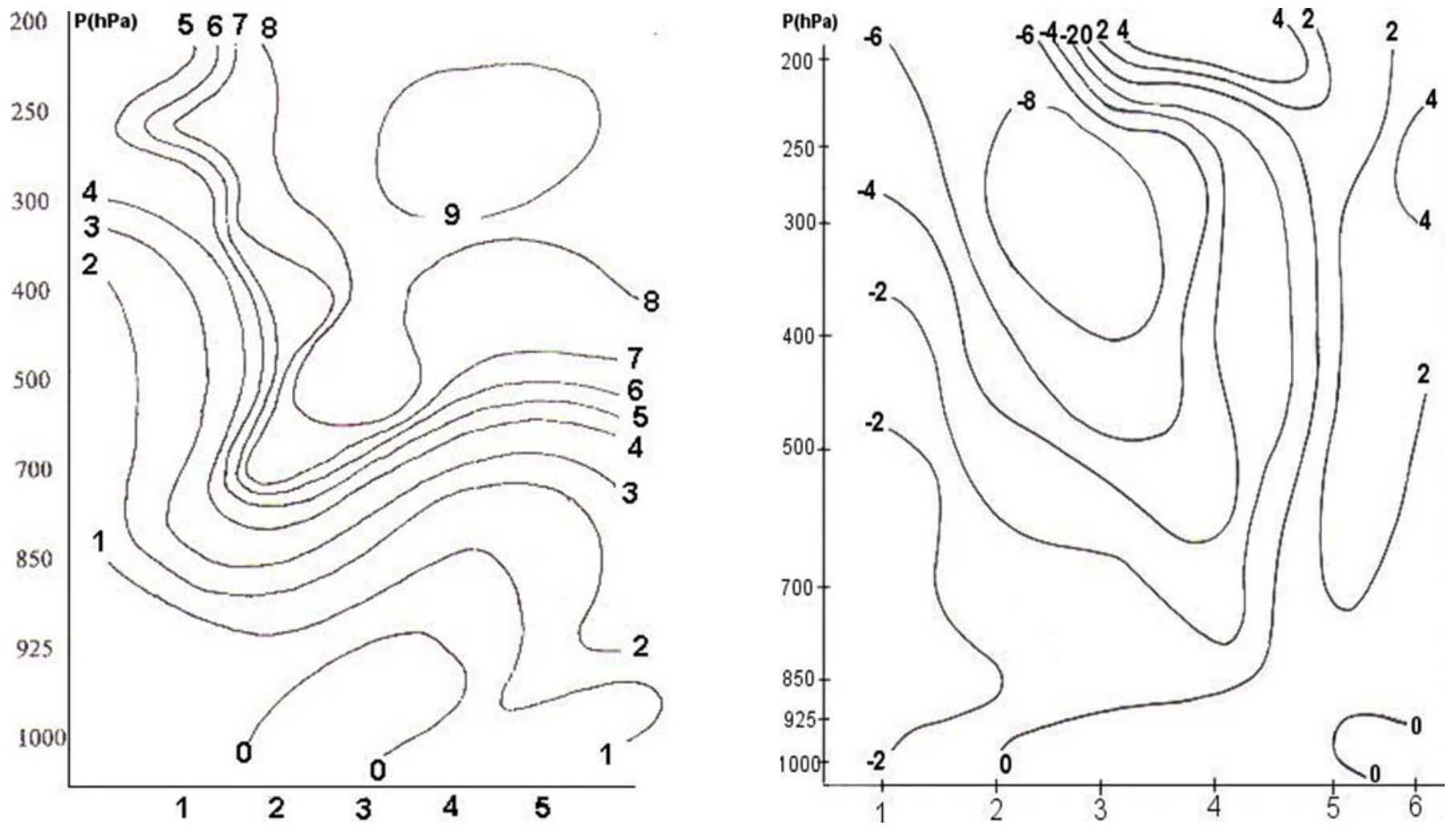

Figura 14 - Seção vertical da vorticidade relativa (a) e perpendicular as frentes (b) 
troposfera foi responsável pelo desenvolvimento de nuvem vírgula (Bonatti, 1988). De acordo com Reed (1979), tanto a instabilidade baroclínica quanto a barotrópica provocam o desenvolvimento de pequenos ciclones. $\mathrm{Na}$ frente secundária a baroclinia ocorreu somente em altos níveis. Em geral, pode ser concluído que a instabilidade baroclínica em altos níveis e a instabilidade barotrópica em baixos níveis foram, provavelmente, responsáveis pela formação da frente secundária.

\section{CONCLUSÕES}

Os resultados mostraram que a frente fria secundária foi observada na parte leste do RS próximo ao oceano Atlântico. Esta frente estava associada com fenômenos adversos, ou seja, com nuvens cumulunimbus, chuvas intensas e, em algumas regiões, com precipitação de neve.

A frente secundária foi observada claramente na imagem de satélite e nos campos de temperatura, umidade, convergência de umidade em baixos níveis e de advecção de vorticidade no nível de $500 \mathrm{hPa}$. Nos campos de pressão, altura geopotencial, divergência e vorticidade, a frente fria secundária não estava bem definida; por isso, a previsão deste tipo de sistema se torna bastante complicada.

Todos os cálculos dos índices de instabilidade não mostraram instabilidade da atmosfera e a possibilidade de formação de precipitações intensas na região da frente secundária. Todavia, a atmosfera apresentava-se condicionalmente instável até $700 \mathrm{hPa}$, e com precipitações intensas. Por isso, estes índices não são confiáveis para identificação da instabilidade no caso de frentes frias secundárias devido à estrutura não homogênea destas frentes.

Através da análise das seções verticais conclui-se, que na região da frente fria secundária a umidade estava bastante elevada em baixos níveis; as isolinhas de temperatura apresentaram-se inclinadas e a vorticidade relativa mostrou valores negativos em torno de $-9 \times 10^{-5}$ entre 300 e $250 \mathrm{hPa}$, na região da frente fria secundária.

A descrição da frente fria secundária feita neste trabalho poderá ajudar aos meteorologistas da área operacional na identificação deste tipo de frente e, conseqüentemente, na elaboração da previsão do tempo de curto prazo.

\section{REFERÊNCIAS}

BONATTI, I. P. Sistemas de vórtices de ar frio do tipo vírgula. Apostila do curso de Modelos Diagnósticos para Previsão do tempo. São Paulo. USP, p. 53-75, 1988.

Browning, k.A. Mesoscale aspects of extratropical cyclones: an observational perspective. In: The life cycles of extratropical cyclones. Boston, AMS, p. 265-283, 1999.
Browning, k.a., monk, g.a. A simple model for the synoptic analysis of cold fronts. Quart. J. roy. Meteor. Soc., v. 108, p. 435-452, 1982.

Carr, f. h. millard, j. p. A composite study of comma clouds and their association with severe weather over the Great Plains. Mon. Wea. Rev., v. 113, p. 370-387, 1985.

DJURIC, D. Weather analysis. Prentice Hall, Upper Saddle River London, 80 pp. 1994.

FEDOROVA, N. Meteorologia Sinótica. V.1, Pelotas. Editora e Gráfica Universitária - UFPel, 259 pp. 1999.

FEDOROVA, N., CARVALHO, M. H. Processos sinóticos em anos de La Niña e de El Niño. Parte II: Zonas frontais. Rev. Bras. Met., v. 15, n. 2, p. 57-72, 2000.

FEDOROVA, N., CARVALHO, M. H., FEDOROV, D. Formação de vórtices no campo de nebulosidade sobre a América do Sul. Rev. Bras. Met., v. 14, n.2, p. 15-27, 1999.

HALLAK, R., SILVA DIAS, M. A. F. Estudo diagnóstico de um vórtice de ar frio - Parte I: Aspectos de grande escala. In CONGRESSO BRASILEIRO DE METEOROLOGIA, 11, 2000, Rio de Janeiro, Anais... Rio de Janeiro, 2000, (Cd-Rom).

MULLEN, S. L. An investigation of small synoptic-scale cyclones in polar air streams. Mon. Wea. Rev., v.107, p. 1636-1647, 1979.

REEDER, M. J., SMITH, R. K. Mesoscale meteorology. In: Meteorology of the Southern Hemisphere. Boston: American Meteorological Society. v. 27, n. 49, p. 201-241, 1998.

SIGNORINI, E., FEDOROVA, N., SILVA, R. S. Encontro entre ciclone térmico e um sistema frontal. Parte I: Análise sinótica e análise da temperatura. In: CONGRESSO BRASILEIRO DE METEOROLOGIA, 10, 1998, Brasília, Anais... Brasília, 1998a, CD-ROM.

SIGNORINI, E., FEDOROVA, N., SILVA, R. S. Encontro entre ciclone térmico e um sistema frontal. Parte III: Análise da vorticidade relativa e divergência horizontal. In: CONGRESSO BRASILEIRO DE METEOROLOGIA, 10, 1998, Brasília, Anais... Brasília, 1998b, CD-ROM.

VASQUEZ, T. Weather forecasting handbook. Weather graphics technologies. Garland, Texas, 75pp. 1994.

VIRJI, H. A preliminary study of summertime tropospheric circulation patterns over South America estimated from cloud winds. Mon. Wea. Rev., v.109, p.599-610, 1981

ZILLMAN, J. W., PRICE, P. G. On the thermal structure of mature Southern Ocean cyclones. Aust. Meteor., 20, p.34-48, 1972.

ZVEREV, A. S. Meteorologia sinótica e base do cálculo do tempo. Leningrad, Hydrometeoisdat, 774 pp. 1968 (em Russo). 